\title{
Incidence of optic disc haemorrhages in chronic simple glaucoma and ocular hypertension
}

\section{J. GLOSTER}

From the Institute of Ophthalmology, University of London, and Moorfields Eye Hospital, London

SUMMARY 1829 photographs of optic discs taken during routine examination and follow-up of 320 glaucoma patients and 169 cases of ocular hypertension were examined for the presence of haemorrhages on the disc. As expected, the observed incidence of disc haemorrhages rose with increase in the number of occasions on which the patient was photographed. It was concluded that at least one-third of glaucoma patients show a disc haemorrhage at one time or another. Disc haemorrhages were seen more often in patients with established glaucoma than in those with ocular hypertension. In patients with chronic simple glaucoma eyes with full fields and low cup: disc ratios showed haemorrhages less often than eyes with field defects and more advanced damage to the optic disc, but apart from this there was no marked tendency for haemorrhages to occur at a particular stage of the disease. Haemorrhages were more frequent in low-tension than in chronic simple glaucoma, but this was probably only part of a more general variation which was revealed when eyes were graded according to the maximum pressures ever recorded, there being a very significant trend in which more haemorrhages were found in eyes with lower than with higher intraocular pressures over the range from 10 to $60 \mathrm{mmHg}$.

Descriptions of haemorrhages on the optic disc in glaucoma $^{12}$ have been followed by studies of the relationship of these haemorrhages to the development of visual field defects, ${ }^{3}$ their importance in prognosis, ${ }^{4}$ and their association with systemic disorders, especially haemodynamic crises, vascular disease, low blood pressure, and diabetes. ${ }^{5}$ With regard to the incidence of these haemorrhages, the reports of various authors show some variation which may be attributed in part to differences in the method and the frequency of examination of the optic disc and to the type of glaucoma. Primrose ${ }^{6}$ reported that, out of 69 new cases of glaucoma seen in 1968, disc haemorrhages were found in 3 patients, 1 of these being regarded as having low-tension glaucoma; in addition, 1 glaucoma suspect was found to have a disc haemorrhage. Kottler and Drance ${ }^{7}$ examined 1000 photographs of the optic discs of patients with established or suspected glaucoma and found 68 which showed haemorrhages. Susanna et al. ${ }^{8}$ compared the prevalence of haemorrhages in chronic simple glaucoma and in ocular hypertension, utilising the

Correspondence to Professor J. Gloster, Institute of Ophthalmology, Judd Street, London WC1H 9QS. records of 84 patients in the former category and 50 patients in the latter, the average number of attendances for examination being 10; they found an incidence of $36.9 \%$ in chronic simple glaucoma and $8.0 \%$ in ocular hypertension. In a recent review of low-tension glaucoma Levene' stated that he was not aware of a controlled comparison of the incidence of disc haemorrhages in chronic simple glaucoma and low-tension glaucoma, but he had the impression of a higher frequency in the latter condition. In his own series of 53 patients with low-tension glaucoma he found haemorrhages in $6(11.3 \%)$, which is similar to the incidence $(8 / 77=10 \cdot 4 \%)$ reported by Chumbly and Brubaker ${ }^{10}$ but lower than that $(11 / 45=24.4 \%)$ given by Drance et al. ${ }^{5}$

Haemorrhages on the optic disc in glaucoma patients vary not only in size but also in intensity, being easily visible immediately after their appearance, but becoming fainter until they finally disappear several weeks later. There can be no doubt that they are sometimes missed by ophthalmoscopy, especially in patients on miotics. It is clear, therefore, that for their accurate enumeration optic disc photography has obvious advantages, and this paper presents results based on the examination of over 1800 photographs. 


\section{Patients and methods}

Photography of the optic disc has formed part of the routine examination and follow-up of a substantial proportion of the patients seen in the Glaucoma Unit of the Institute of Ophthalmology, London, and Moorfields Eye Hospital over the past 7 years. Full descriptions of the photographic procedures and measurement of the cup: disc ratios have been given in previous papers. ${ }^{1112} \mathrm{~A}$ total of 2714 colour transparencies were found to be of sufficiently good quality to allow a reasonably confident opinion to be given as to the presence or absence of a disc haemorrhage, and they were examined in the alphabetical order of the patients' names. When all the results had been recorded, the diagnosis and other clinical details were added. The findings for certain groups of patients were excluded from the analysis. These were patients who after full examination were regarded as having normal intraocular pressures and no signs of glaucoma, patients with closed-angle glaucoma or secondary glaucoma, and patients in whom some doubt as to the exact diagnosis remained even after exhaustive investigation. This latter group included 'glaucoma suspects', the main reason for placement in this category being doubt about the presence or absence of an early field defect. After these exclusions 1829 photographs remained in the analysis, and these comprised: (a) 1315 photographs of 617 eyes of 320 patients who had a definite glaucomatous type of field defect associated with characteristic optic disc changes in one or both eyes (chronic simple glaucoma and low tension glaucoma), and (b) 514 photographs of 284 eyes of 169 patients who had an intraocular pressure exceeding $21 \mathrm{mmHg}$ in one or both eyes but no field defect (ocular hypertension). Patients with ocular hypertension were further divided into those who had a positive family history of glaucoma and those who did not. Some patients had been photographed on one occasion only whereas in others photography had been repeated on several occasions, the details being given below. In most cases more than one transparency was available for each occasion on which photography was performed, and these duplicates were often useful when checking the presence of very small haemorrhages.

\section{Results}

In the early stages of examining the photographs it became clear that there was some variation in the appearance of haemorrhages found on the optic disc in glaucoma patients. The majority had the characteristic appearance for which the term 'splinter haemorrhage' is an apt descriptive term, but others lacked this linear radial quality and had a blotchy, rounded shape. It was difficult to define exactly those haemorrhages which should and those which should not be counted. There were some photographs in which disc haemorrhages were seen in conjunction with evidence of relatively gross vascular pathologyfor example, past venous occlusion-and these were excluded from the analysis, and the same rule was applied when retinal haemorrhages were seen elsewhere in the photograph. The haemorrhages which were included in the analysis were therefore usually solitary, although in 3 eyes 2 haemorrhages were present. They lay in the neuroretinal rim tissue between the edge of the cup and the edge of the disc, or in the peripapillary tissue but touching the edge of the disc, or across the edge of the disc. The most frequent site of the haemorrhages was in the inferotemporal sector of the disc. In 2 patients faint, blotchy haemorrhages were observed in the floor of the cup in the disc.

Very faint reddish marks on the photographs raised problems. If present in more than one photograph taken on the same day, and, if absent from photographs taken on another occasion, they were counted as haemorrhages, although this introduced a slight bias towards finding more haemorrhages in eyes photographed more than once. If doubt remained, the photograph was excluded from the analysis.

Table 1 summarises the observations made on 1315 photographs of 617 glaucomatous eyes; slightly more than half of these were photographed once only, and the details of repeated photography on the remainder are given in the table. The table also shows the number of eyes in which haemorrhages were found, including eyes in which haemorrhages were observed on more than one occasion. As would be expected, the observed incidence of haemorrhage increased the more times photography was done. Statistical analysis showed that this trend was significant,

Table 1 Incidence of optic disc haemorrhages in relation to the number of occasions on which disc photography was done on glaucomatous patients

\begin{tabular}{|c|c|c|c|c|c|c|c|}
\hline & \multicolumn{7}{|c|}{ Number of occasions on which photographs were taken } \\
\hline & 1 & 2 & 3 & 4 & 5 & 6 & 7 \\
\hline \multicolumn{8}{|c|}{$\begin{array}{l}\text { Number of eyes } \\
\text { photographed } \\
\text { (617) }\end{array}$} \\
\hline $\begin{array}{l}\text { Number of eyes } \\
\text { with disc } \\
\text { haemorrhages }(60)\end{array}$ & & & & & & & \\
\hline on 1 occasion & 16 & 16 & 7 & 3 & 4 & 5 & 1 \\
\hline on 2 occasions & - & $\mathbf{0}$ & 1 & 0 & 2 & 2 & 1 \\
\hline on 3 occasions & - & - & $\mathbf{0}$ & 1 & 0 & $\mathbf{0}$ & $\mathbf{0}$ \\
\hline on 4 occasions & - & - & - & 0 & 0 & 0 & 1 \\
\hline $\begin{array}{c}\text { Total } \\
\text { Incidence of disc }\end{array}$ & 16 & 16 & 8 & 4 & 6 & 7 & 3 \\
\hline haemorrhage & $4.9 \%$ & $14 \cdot 2 \%$ & $12 \cdot 1 \%$ & $8.9 \%$ & $18 \cdot 8 \%$ & $26.9 \%$ & $30.0 \%$ \\
\hline
\end{tabular}


Table 2 Incidence of optic disc haemorrhages in relation to the amount of field loss

\begin{tabular}{llll}
\hline $\begin{array}{l}\text { Amount of } \\
\text { field loss }\end{array}$ & $\begin{array}{l}\text { Number of } \\
\text { eyes in group }\end{array}$ & $\begin{array}{l}\text { Number of } \\
\text { eyes with disc } \\
\text { haemorrhage }\end{array}$ & $\begin{array}{l}\text { Incidence of } \\
\text { disc haemorrhage }\end{array}$ \\
\hline None & 158 & 11 & $7 \cdot 0 \%$ \\
Early & 124 & 16 & $13 \cdot 0 \%$ \\
Intermediate & 125 & 17 & $13 \cdot 7 \%$ \\
Advanced & 128 & 12 & $9 \cdot 4 \%$ \\
\hline
\end{tabular}

Table 3 Incidence of optic disc haemorrhages in relation to the vertical cup: disc ratio in glaucoma patients

\begin{tabular}{lllll}
\hline $\begin{array}{l}\text { Range of vertical } \\
\text { cup: disc ratio }\end{array}$ & $\begin{array}{l}\text { Number } \\
\text { of eyes }\end{array}$ & $\begin{array}{l}\text { Number } \\
\text { of eyes } \\
\text { with disc } \\
\text { haemorrhage }\end{array}$ & $\begin{array}{l}\text { Incidence } \\
\text { of disc } \\
\text { haemorrhage }\end{array}$ & $\begin{array}{l}\text { Average } \\
\text { number of } \\
\text { times each } \\
\text { eye was } \\
\text { photographed }\end{array}$ \\
\hline Up to 0.69 & 159 & 9 & $5.7 \%$ & $2 \cdot 10$ \\
0.70 to 0.79 & 119 & 16 & $11.9 \%$ & 2.51 \\
0.80 to 0.89 & 126 & 18 & $12.5 \%$ & 2.16 \\
0.90 to 1.00 & 64 & 13 & $16.9 \%$ & 2.27 \\
\hline
\end{tabular}

Table 4 Incidence of optic disc haemorrhages in chronic simple glaucoma, low-tension glaucoma and ocular hypertension

\begin{tabular}{llll}
\hline Diagnosis & $\begin{array}{l}\text { Number } \\
\text { of } \\
\text { eyes }\end{array}$ & $\begin{array}{l}\text { Eyes with } \\
\text { disc } \\
\text { haemorrhage }\end{array}$ & $\begin{array}{l}\text { Incidence } \\
\text { of disc } \\
\text { haemorrhage }\end{array}$ \\
\hline $\begin{array}{l}\text { Chronic simple glaucoma } \\
\text { Eyes with field defects } \\
\text { Eyes with full fields }\end{array}$ & 392 & 36 & $9 \cdot 2 \%$ \\
$\begin{array}{l}\text { Low-tension glaucoma } \\
\text { Eyes with field defects }\end{array}$ & 142 & 6 & $4 \cdot 2 \%$ \\
$\begin{array}{l}\text { Eyes with full fields } \\
\begin{array}{l}\text { Ocular hypertension } \\
\text { Positive family history } \\
\text { of glaucoma }\end{array}\end{array}$ & 16 & 13 & $19 \cdot 4 \%$ \\
$\begin{array}{l}\text { No family history of } \\
\text { glaucoma }\end{array}$ & 86 & 5 & $31 \cdot 3 \%$ \\
\hline
\end{tabular}

although the rate of increase was not established with sufficient accuracy for a reliable conclusion to be drawn about the true incidence of disc haemorrhages in glaucoma - that is, if an unlimited number of photographs had been taken on all patients over a long period of time. It is clear, however, from Table 1 that optic disc haemorrhages were relatively common in glaucoma, and it is probable that at least one-third of affected eyes showed them at some time or another. When the results were analysed in terms of patients rather than eyes, it was found that 54 out of 320 glaucoma patients $(16.9 \%)$ had disc haemorrhages.

The stage to which chronic simple glaucoma has progressed in the individual patient may be expressed by the amount of visual field loss or by the amount of optic disc damage as indicated by the vertical cup: disc ratio. ${ }^{13}$ This information was available for some of the patients in this study and was used to discover if there was any relationship between the incidence of haemorrhage and the stage of the disease, the results being summarised in Tables 2 and 3 . In Table 2 eyes have been grouped according to whether they had full fields or early, intermediate, or advanced field loss. An eye with a full field was included only if the other eye had a definite glaucomatous field defect; thus in Table 2 all eyes were in patients who had chronic simple or low-tension glaucoma. 'Early' field loss was an arcuate scotoma or lesser defect. If such a scotoma had enlarged and broken out to the periphery it was regarded as 'intermediate'. 'Advanced' field loss was more extensive. It can be seen that eyes with full fields in glaucoma patients had a lower incidence of disc haemorrhage than those showing field defects, but in the latter group statistical analysis did not reveal a significant relationship between the incidence of haemorrhage and the degree of field loss. Table 3, however, shows a rising incidence of haemorrhage as the vertical cup: disc ratio increases, and this trend is statistically significant $\left(\chi^{2}=7 \cdot 60, p<0.001\right)$. It is highly unlikely that this result can be explained on the basis of more frequent photography in patients with large cup: disc ratios than in those with small ratios, because Table 3 shows that there was little variation in this factor.

Details of the incidence of haemorrhages in various diagnostic categories are given in Table 4. Statistical analysis showed that the incidence of haemorrhages was significantly lower $\left(\chi^{2}=11.7,0.01>p>0.001\right)$ in ocular hypertension than in chronic simple glaucoma, and that the incidence was significantly higher $\left(\chi^{2}=14 \cdot 1, p<0 \cdot 001\right)$ in low-tension glaucoma than in chronic simple glaucoma. The classification into low-tension or chronic simple glaucoma is dependent upon the selection of a dividing level of intraocular pressure. In this study patients who had at some time shown a pressure of $21 \mathrm{mmHg}$ or above in either eye were regarded as having chronic simple glaucoma, while the remainder were put in the lowtension category. The arbitrary nature of this separation is well recognised, and therefore the results were analysed further by placing the eyes in groups according to the maximum pressure recorded. The clinical records for each patient were scrutinised and the highest pressure recorded on any occasion for each eye was noted. Usually this was a pressure measured before treatment was started, and in some instances it had been recorded several years before the photograph was taken. In some patients it was considered that adequate information on the maximum intraocular pressure was not availablefor example, sometimes when treatment had been started in other hospitals-and such patients were 
omitted from the analysis. The results are summarised in Table 5 , which shows a clear and highly significant trend $\left(\chi^{2}=10.30, \mathrm{p}<0.001\right)$ in which glaucomatous eyes with lower pressures had a higher incidence of optic disc haemorrhages than those with higher pressures. This could not be attributed to a greater frequency of photography in one group as compared with another, because Table 5 shows only a small variation in the average number of photographs for each eye in the various groups and statistical analysis showed no significant trend in this factor.

\section{Discussion}

Clinical observations suggest that a haemorrhage may appear on the optic disc of a glaucoma patient, remain visible for a few weeks, and then disappear. After a certain time, perhaps a matter of months, another haemorrhage may appear in the same or in a different part of the disc. The more often observations are made on a patient the more likely it is that a haemorrhage will be found at some time or another. The results in Table 1 show this clearly but do not permit a reliable extrapolation to be made in order to answer the question of whether all or only a proportion of glaucomatous optic discs bear haemorrhages at some time or another. It would seem that a large survey would be needed, involving the photography at regular intervals of several hundred glaucomatous eyes probably over a period of 5-10 years. Nevertheless it is of interest that this study suggests that the incidence of haemorrhages in eyes photographed repeatedly over several years would be around $30 \%$, which is in reasonable agreement with the incidence of $36.9 \%$ given for chronic simple glaucoma by Susanna et al. ${ }^{8}$ Also in agreement with these workers was the finding of a significantly lower incidence of disc haemorrhages in ocular hypertension, but the number of eyes with haemorrhages was too small for any valid conclusion to be drawn about the possible significance of a positive family history of glaucoma in relation to the occurrence of disc haemorrhage in ocular hypertension.

Table 5 Incidence of disc haemorrhages in relation to the maximum recorded intraocular pressure in glaucoma patients

\begin{tabular}{lllll}
\hline $\begin{array}{l}\text { Maximum } \\
\text { IOP in range } \\
\mathrm{mmHg}\end{array}$ & $\begin{array}{l}\text { Number of } \\
\text { eyes }\end{array}$ & $\begin{array}{l}\text { Number of } \\
\text { eyes with } \\
\text { disc } \\
\text { haemorrhage }\end{array}$ & $\begin{array}{l}\text { \% incidence } \\
\text { of disc } \\
\text { haemorrhage }\end{array}$ & $\begin{array}{l}\text { Average } \\
\text { number of } \\
\text { times each } \\
\text { disc was } \\
\text { photographed }\end{array}$ \\
\hline $11-20$ & 66 & 12 & $18 \cdot 2 \%$ & $2 \cdot 34$ \\
$21-30$ & 208 & 26 & $12.5 \%$ & $2 \cdot 25$ \\
$31-40$ & 91 & 6 & $6.6 \%$ & 2.35 \\
$41-50$ & 40 & 1 & $2 \cdot 5 \%$ & 1.73 \\
$51-60$ & 13 & 0 & $0 \%$ & 1.87 \\
\hline
\end{tabular}

Examination of the relationship between the incidence of disc haemorrhage and the amount of glaucomatous field loss did not allow any clear conclusion to be reached. When glaucomatous eyes with field loss were compared with their fellow eyes which had full fields, there seemed to be a difference between chronic simple and low-tension glaucoma (Table 4). In the former disease eyes with full fields had fewer haemorrhages than eyes with field defects, while in low-tension glaucoma the reverse was the case. There were, however, relatively few eyes with no field defects, and statistical analysis showed that the differences were not significant. In eyes with field defects no significant relationship was found between the incidence of haemorrhages and the amount of field loss (Table 2). On the other hand, when the stage of the disease was assessed by the amount of cupping of the optic disc, it was found that there was a significant increase in the incidence of haemorrhage as the vertical cup: disc ratio increased (Table 3). Nevertheless the general impression from these results is that there is no particular stage of the disease at which haemorrhages predominate.

The most interesting outcome of this study is the finding that the incidence of disc haemorrhage was greater in eyes with lower intraocular pressures than in eyes with higher pressures, the pressures referred to being the maximum values ever recorded, usually before treatment had started and sometimes several years before photography. When the artificial diagnostic division was made into low-tension and chronic simple glaucoma, this variation showed itself in a higher incidence of haemorrhages in the former group than in the latter. The intraocular pressure at the time of occurrence of the haemorrhage was of course unknown and did not necessarily bear any relationship to the untreated pressure or to the pressure at the time of photography, which was often modified by cessation of miotics and dilatation of the pupil and, in some cases, by the temporary use of carbonic anhydrase inhibitors. The only assumption which can perhaps be made is that there was probably a greater uniformity of pressure in the eyes at the time of haemorrhage, since most eyes were on treatment then, than when the maximum pressures were recorded.

It may be that the association of a higher incidence of disc haemorrhage with lower intraocular pressure is no more than a reflection of an increased vulnerability of the tissues in some glaucomatous eyes, the blood vessels being unusually fragile and the optic nerve head lacking resistance to damage by an intraocular pressure at or only slightly above the normal level. Alternatively it may be that in some glaucomatous eyes there is an ischaemic process which in the posterior segment is responsible for the haemorrhages 
and an increased vulnerability of the tissues to pressure, and in the anterior segment causes reduced aqueous formation which limits the elevation of intraocular pressure. The present results allow no more than the formulation of such hypotheses in very general terms, but the relationship between intraocular pressure and disc haemorrhage clearly merits further study.

I am grateful to members of the staff of the Glaucoma Clinic of the Institute of Ophthalmology and Moorfields Eye Hospital who helped in the collection of clinical details of the patients and, in particular, to Mr D. Poinoosawmy, who took most of the optic disc photographs. I would also like to thank Mr Hugh Donovan of the Computer Section, Institute of Ophthalmology, for the statistical analysis of the results.

\section{References}

1 Drance SM, Begg IS. Sector haemorrhage'-a probable acute ischaemic disc change in chronic simple glaucoma. Can $J$ Ophthalmol 1970; 5: 137-41.

2 Begg IS, Drance SM, Sweeney VP. Ischaemic optic neuropathy in chronic simple glaucoma. Br J Ophthalmol 1971; 55: 73-90.
3 Begg IS, Drance SM. Progress of the glaucomatous process related to recurrent ischaemic changes at the optic disc. Exp Eye Res 1971; 11: 141.

4 Drance SM, Fairclough M, Butler DM, Kottler MS. The importance of disc hemorrhage in the prognosis of chronic open angle glaucoma. Arch Ophthalmol 1977; 95: 226-8.

5 Drance SM, Sweeney VP, Morgan RW, Feldman F. Studies of factors involved in the production of low tension glaucoma. Arch Ophthalmol 1973; 89: 457-65.

6 Primrose J. Early signs of the glaucomatous disc. Br JOphthalmol 1971; 55: 820-5.

7 Kottler MS, Drance SM. Studies of hemorrhage on the optic disc. Can J Ophthalmol 1976; 11: 102-5.

8 Susanna R, Drance SM, Douglas GR. Disc hemorrhages in patients with elevated intraocular pressure. Occurrence with and without field changes. Arch Ophthalmol 1979; 97: 284-5.

9 Levene RZ. Low tension glaucoma: a critical review and new material. Surv Ophthalmol 1980; 24: 621-64.

10 Chumbly LC, Brubaker RF. Low tension glaucoma. Am J Ophthalmol 1976; 81: 761-7.

11 Gloster J, Parry DG. The use of photographs for measuring cupping in the optic disc. Br J Ophthalmol 1974; 58: 850-62.

12 Gloster J. Vertical ovalness of glaucomatous cupping. $\mathrm{Br} J$ Ophthalmol 1975; 59: 721-4.

13 Gloster J. Quantitative relationship between cupping of the optic disc and visual field loss in chronic simple glaucoma. $\mathrm{Br} J$ Ophthalmol 1978; 62: 665-9. 